\title{
DETERMINATION OF LEVELS OF GLUCOSAMINE HYDROCHLORIDE AND CHONDROITIN SULFATE IN MIXTURES IN TABLET AND CREAM FORMS USING HIGH-PERFORMANCE LIQUID CHROMATOGRAPHY WITH FLUORESCENCE
}

\author{
HARMITA HARMITA, CATUR JATMIKA, MUFID IDAN NUGRAHA*
}

Department of Pharmacy, Faculty of Pharmacy, Universitas Indonesia, Depok, Indonesia. Email: mufidanugraha@gmail.com Received: 21 April 2017, Revised and Accepted: 18 August 2017

\begin{abstract}
Objective: Glucosamine hydrochloride ( $\mathrm{HCl}$ ) and chondroitin sulfate are glycosaminoglycan compounds and major structural components of bones in the form of proteoglycans. These compounds maintain bone structure by stimulating the synthesis of synovial fluid and inhibiting the degradation of joint cartilage, and they can be used for the treatment of osteoarthritis. The aim of this study was to identify a selective analytical method for determining glucosamine $\mathrm{HCl}$ and chondroitin sulfate levels in tablet and cream forms.

Methods: After derivatization using ortho-phthalaldehyde and 2-mercaptoethanol, the samples were analyzed using high-performance liquid chromatography (HPLC) with a fluorescence detector at an excitation wavelength of $335 \mathrm{~nm}$ and an emission wavelength of $445 \mathrm{~nm}$. Deacetylation using sodium hydroxide was required to break the acetyl group bond. The mobile phase used tetrahydrofuran $0.25 \%$ in water-acetonitrile (87:13) with a flow rate of $1.5 \mathrm{ml} / \mathrm{minute}$.
\end{abstract}

Results: The average levels of glucosamine $\mathrm{HCl}$ and chondroitin sulfate were $92.76 \%$ and $96.11 \%$ in tablets and $101.15 \%$ and $100.33 \%$ in creams, which fulfilled the acceptance criteria.

Conclusions: Our validation method for glucosamine $\mathrm{HCl}$ and chondroitin sulfate met the acceptance criteria of accuracy, precision, selectivity, and linearity.

Keywords: Chondroitin sulfate, Derivatization, Glucosamine hydrochloride, Fluorescence, High-performance liquid chromatography, Validation.

(C) 2017 The Authors. Published by Innovare Academic Sciences PvtLtd. This is an open accessarticle under the CC BY license (http://creativecommons. org/licenses/by/4. 0/) DOI: http://dx.doi.org/10.22159/ijap.2017.v9s1.75_82

\section{INTRODUCTION}

Glucosamine(2-amino-2-deoxy-D-glucose) is an amino monosaccharide, a component of glycoproteins in connective tissues and mucous membranes, involved in the formation of glycosaminoglycans. For two decades, the salt forms of glucosamine (hydrochloride $[\mathrm{HCl}]$ and sulfate) have been used independently or together with other active ingredients such as chondroitin sulfate in capsules, tablets, and solutions for oral administration. At present, topical forms of glucosamine, such as creams, gels, and patches, are being developed by the pharmaceutical industry [1]. Glucosamine $\mathrm{HCl}$ and chondroitin sulfate are used to treat osteoarthritis (OA). Glucosamine $\mathrm{HCl}$ stimulates improved joint function, and various studies have shown that it reduces the pain of $\mathrm{OA}$, rehabilitates cartilage, improves synovial fluid formation, and improves joint damage caused by OA. Chondroitin sulfate supports cartilage health by absorbing liquids (especially water) into the connective tissue, and it can reduce the pain of $\mathrm{OA}$ and act as an anti-inflammatory medication [2].

The prevalence of $\mathrm{OA}$ in Indonesians older than 65 years is $60.5 \%$ in men and $70.5 \%$ in women, with approximately 2 million people suffering from a disability due to $\mathrm{OA}$ [3]. The increased prevalence of $\mathrm{OA}$ has led to a growing need for pharmaceuticals containing glucosamine and chondroitin. Therefore, a selective analysis method is required to ensure the quality of different pharmaceutical delivery forms [4].

Based on a search of literature, analysis of glucosamine $\mathrm{HCl}$ can be performed using high-performance liquid chromatography (HPLC) with a fluorescence detector. Glucosamine $\mathrm{HCl}$ does not have chromophore groups in the ultraviolet/visible (UV/Vis) spectra, but it can form fluorescence compounds after being derivatized with a fluorogenic reagent. Commonly used reagents for analyzing the derivatization of glucosamine $\mathrm{HCl}$ include ortho-phthalaldehyde (OPA), phenylisothiocyanate, and 9-fluorenylmethoxycarbonyl chloride [4]. Several methods are used to analyze chondroitin sulfate, such as titration with cetylpyridinium chloride, which enables the analysis of compounds with large molecules such as proteins but not specifically chondroitin sulfate [5]. Another technique for analyzing chondroitin sulfate is ion exchange chromatography with a fluorescence detector, commonly involving enzymatic digestion [6].

Several studies have analyzed mixtures of glucosamine $\mathrm{HCl}$ and chondroitin sulfate, including isotachophoresis and ionic analyte separation techniques using electrophoresis with UV detection at $254 \mathrm{~nm}$ [7]. Ion exchange chromatography is performed using a CarboPac PA20 column with potassium hydroxide as the eluent, with a flow rate of $0.5 \mathrm{ml} / \mathrm{minute}$ at $30^{\circ} \mathrm{C}$ [8]. Previous studies have also used reverse-phase HPLC with a fluorescence detector to analyze a mixture of glucosamine $\mathrm{HCl}$ and chondroitin sulfate in the Laboratory Quality Testing Center of Drugs, Food and Cosmetics Faculty of Pharmacy, Universitas Indonesia. The present study aimed to conduct further research on the optimization, validation, and determination of glucosamine $\mathrm{HCl}$ and chondroitin sulfate levels in tablet and cream forms using HPLC with a fluorescence detector. The expected advantage of this technique was that the results would be more selective than with a UV detector.

\section{MATERIALS AND METHODS}

\section{Chemical and reagents}

Standard glucosamine HCl (Sigma-Aldrich, US), standard chondroitin sulfate (PT. Dua Lima Farma, Indonesia), Aqua Bidest (PT. Ikapharmindo PUTRAMAS, Indonesia), Acetonitrile Pro HPLC (Merck, US/Canada), tetrahydrofuran (THF, Mallinckrodt chromAR® HPLC, US), OPA (Bio 
Basic Inc., Canada), 2-mercaptoethanol (Merck, US/Canada), boric acid (Merck, US Canada), and NaOH (Merck, US Canada); Methanol Pro HPLC (Merck, US Canada), hydrochloric acid (Merck, US Canada), and dichloromethane (Merck, US/Canada).

\section{Samples}

Caplet Viostin DS ${ }^{\circledR}$ (Pharos, Indonesia) and Flexamine Cream ${ }^{\circledR}$ (Novell Pharmaceutical, Indonesia) were used.

\section{Instruments}

LC-20AT (Shimadzu, Japan) equipped with a pump, YMC-Triart® C18 column $(250 \times 4.6 \mathrm{~mm}, 5 \mu \mathrm{m}), 20 \mathrm{~A} \mathrm{RF}$ fluorescence detector (Shimadzu, Japan), manual injector, data processor, HPLC syringes (SGE, Australia), centrifuge (Kubota, Japan), vortex (Thermo Scientific, US), micropipettes (Eppendorf, Germany), $0.45 \mu \mathrm{m}$ filter membranes, analytical balance, ultrasonic cleaner (Elma Elmasonic S40H, Germany), and glass tools.

\section{Chromatography system}

This study implemented HPLC equipped with a pump, a C18 column, and a fluorescence detector at $\lambda_{\mathrm{ex}}=335 \mathrm{~nm}$ and $\lambda_{\mathrm{em}}=445 \mathrm{~nm}$. Mobile phase THF in water-acetonitrile (87:13) was used at a flow rate of $1.5 \mathrm{ml} /$ minute.

\section{Preparation of standard solutions}

\section{Standard solution of glucosamine $\mathrm{HCl}$}

Standard glucosamine $\mathrm{HCl}$ was weighed at $50 \mathrm{mg}$, then diluted with $10 \mathrm{ml}$ of methanol:water (2:1), and Aqua Bidest was added up to $50 \mathrm{ml}$. This was diluted to obtain a concentration of $10 \mu \mathrm{g} / \mathrm{ml}$.

\section{Standard solution of chondroitin sulfate}

The chondroitin sulfate standard was weighed at $50 \mathrm{mg}$, then $10 \mathrm{ml}$ of $\mathrm{NaOH} 6 \mathrm{~N}$ was added to a $100 \mathrm{ml}$ glass beaker. This was heated at $60^{\circ} \mathrm{C}$ for 30 minutes with stirring until homogenized, cooled, and then neutralized to $\mathrm{pH} 7$ with $\mathrm{HCl} 2 \mathrm{~N}$. It was then diluted with $10 \mathrm{~mL}$ of methanol:water (2:1), Aqua Bidest was added up to $50 \mathrm{~mL}$, and the mixture was diluted to obtain a concentration of $100 \mu \mathrm{g} / \mathrm{ml}$.

\section{Preparation of tablet sample solution}

Ten tablets were obtained and weighed to calculate the average mass; then the tablets were crushed into a homogeneous powder. The tablets were equivalent to $\pm 100 \mathrm{mg}$.

\section{Sample preparation of glucosamine $\mathrm{HCl}$}

Tablet samples were weighed to $\pm 216 \mathrm{mg}$ and diluted with $10 \mathrm{ml}$ of methanol:water (2:1). The solution was centrifuged at $3500 \mathrm{rpm}$ for 10 minutes, $5 \mathrm{ml}$ of dichloromethane was added, and the solution was shaken for 5 minutes, then allowed to separate. The water layer was filtered with $0.45 \mu \mathrm{m}$ filter membranes. Aqua Bidest was added and diluted to a certain concentration.

\section{Sample preparation of chondroitin sulfate}

Tablet samples were weighed to $\pm 265 \mathrm{mg}$, then placed with $10 \mathrm{~mL}$ of $\mathrm{NaOH} 6 \mathrm{~N}$ in a $100 \mathrm{ml}$ glass beaker. This was heated at $60^{\circ} \mathrm{C}$ for 30 minutes with stirring, cooled, neutralized to $\mathrm{pH} 7$ with $\mathrm{HCl} 2 \mathrm{~N}$, then diluted with $10 \mathrm{ml}$ of methanol:water (2:1). The solution was centrifuged at $3500 \mathrm{rpm}$ for 10 minutes, and $5 \mathrm{~mL}$ dichloromethane was added. The solution was shaken for 5 minutes, then allowed to separate. The water layer was filtered with a $0.45 \mu \mathrm{m}$ filter membrane, then Aqua Bidest was added and diluted to a certain concentration.

\section{Preparation of cream sample solution}

Sample preparation of glucosamine $\mathrm{HCl}$

The cream was weighed out in equivalents of $\pm 250 \mathrm{mg}$, then dissolved in $10 \mathrm{ml}$ of methanol:water $(2: 1)$ and the solution was centrifuged at $3500 \mathrm{rpm}$ for 10 minutes. Next, $5 \mathrm{ml}$ of dichloromethane was added and the solution was shaken for 5 minutes, then allowed to separate. The water layer was filtered with a $0.45 \mu \mathrm{m}$ filter membrane, and then Aqua Bidest was added and diluted to a certain concentration.

Sample preparation of chondroitin sulfate

The cream was weighed in equivalents of $\pm 5 \mathrm{~g}$ and then added to $10 \mathrm{ml}$ of $\mathrm{NaOH} 6 \mathrm{~N}$ in a $100 \mathrm{ml}$ glass beaker. This was heated at $60^{\circ} \mathrm{C}$ for 30 minutes with stirring, then cooled and neutralized to $\mathrm{pH} 7$ with $2 \mathrm{~N} \mathrm{HCl}$. The solution was then diluted with $10 \mathrm{ml}$ of methanol:water (2:1) and centrifuged at $3500 \mathrm{rpm}$ for 10 minutes. Next, $5 \mathrm{ml}$ of dichloromethane was added and the solution was shaken for 5 minutes, and then allowed to separate. The water layer was filtered with a $0.45 \mu \mathrm{m}$ filter membrane, and then Aqua Bidest was added and diluted to a certain concentration.

\section{Derivatization}

Pipettes of $100 \mu \mathrm{l}$ of standard solutions of glucosamine $\mathrm{HCl}$ and chondroitin sulfate were placed in a vial at a concentration of $100 \mu \mathrm{g} / \mathrm{ml}, 50 \mu \mathrm{l}$ of OPA/2-ME reagent was added, and the mixture was homogenized with a vortex for 20 seconds. This was allowed to react for 2 minutes and was then analyzed with the HPLC system (Figs. 1 and 2).

\section{RESULTS AND DISCUSSION}

Analyses of glucosamine $\mathrm{HCl}$ and chondroitin sulfate levels were performed with pre-column derivatization using OPA with the addition of 2-mercaptoethanol (2-ME). Both of these form fluorescent compounds that can be detected. OPA/2-ME is commonly used as a reagent to improve the detection of amino acids. It reacts with the primary amine group substrate to form isoindole derivatives with high molar absorptivity of UV light (chromophores) or fluorescence groups (fluorophores). Glucosamine has primary amine groups $\left(\mathrm{NH}_{2}\right)$ that can be derivatized with OPA/2-ME, while chondroitin has an acetyl group on the amine. Thus, $\mathrm{NaOH}$ is used to break the bond between the acetyl group $\left(\mathrm{COCH}_{3}\right)$ and the nitrogen atom to form primary amine groups $\left(\mathrm{NH}_{2}\right)[9,10]$.

\section{Optimization of derivatization reagent volume and incubation} time

Experiments were conducted to determine the volume of OPA/2-ME reagents required to produce optimum and stable derivatives (Table 1). Volumes of $25 \mu \mathrm{l}, 50 \mu \mathrm{l}$, and $100 \mu \mathrm{l}$ were analyzed, and the $50 \mu \mathrm{l}$ volume showed larger peak areas and was more stable in both compounds. Derivatization produces perfect derivative compounds, so the analyte must be incubated after derivatization at a specific time (Table 2).

Table 1: Optimization of derivatization reagent volume

\begin{tabular}{lll}
\hline Volume $(\boldsymbol{\mu l})$ & Area $(\boldsymbol{\mu v} / \mathbf{s})$ & \\
\cline { 2 - 3 } & Glucosamine HCl & Chondroitin sulfate \\
\hline 25 & 40172900 & 1448830 \\
& 45389489 & 2034847 \\
50 & 40131451 & 2013597 \\
& 41932818 & 2261195 \\
100 & 41751503 & 2120182 \\
& 40008905 & 1920195 \\
& 27697397 & 1407211 \\
& 27726704 & 1117807 \\
\hline
\end{tabular}

HCl: Hydrochloride

Table 2: Incubation times

\begin{tabular}{lll}
\hline \multirow{2}{*}{ Time (minutes) } & Area & \\
\cline { 2 - 3 } & Glucosamine HCl & Chondroitin sulfate \\
\hline 2 & 36067148 & 1169841 \\
5 & 33926297 & 1225551 \\
10 & 34540488 & 1329426 \\
\hline
\end{tabular}




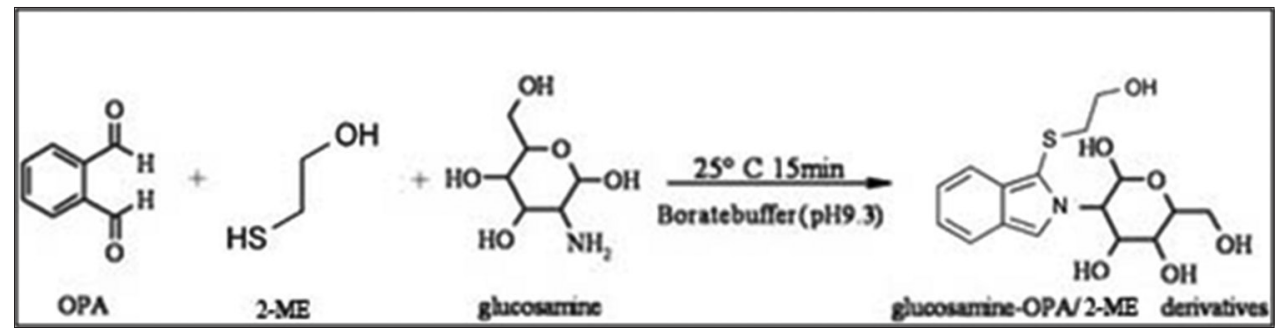

Fig. 1: Derivatization reaction of glucosamine hydrochloride [11,12]

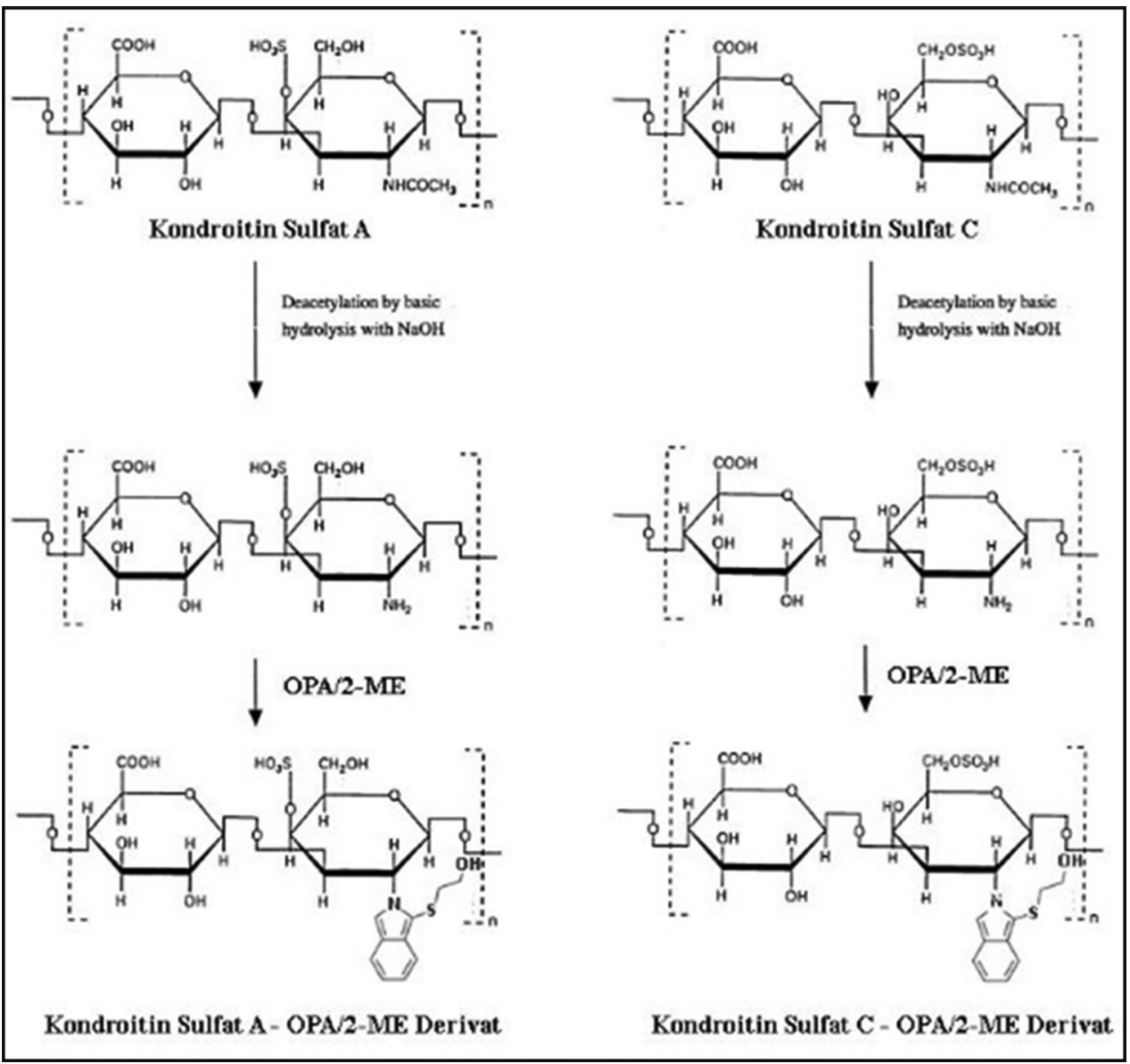

Fig. 2: Derivatization reaction of chondroitin sulfate [10]

Derivatization was compared at 2,5 , and 10 minutes, and the results showed that the optimum derivatization time was 2 minutes.

\section{Chromatography optimization}

The following parameters were optimized, among others: Column type, mobile phase composition, flow rate, injection volume, and injection method. The selected column was the YMC-Triart ${ }^{\circledR}$ C18 $(250 \times 4.6 \mathrm{~mm}$, $5 \mu \mathrm{m})$. The injection method was manual, and the injection volume was $20 \mu$ l. Optimization of the mobile phase was performed by isocratic elution by changing the ratio of the mobile phase (THF $0.25 \%$ in wateracetonitrile) with the composition ratio $(70: 30,80: 20,85: 15,87: 13$, $89: 11$, and 95:5), at a flow rate of $1.5 \mathrm{ml} /$ minute. Two injections were performed. The results for optimization of mobile phase and flow rate are shown in Tables 3 and 4.

\section{Validation}

\section{Linearity and range}

The calibration curve consisted of a minimum six standard solutions in a linear range of 5-80 $\mu \mathrm{g} / \mathrm{mL}$ for glucosamine $\mathrm{HCl}$ and $100-1000 \mu \mathrm{g} / \mathrm{ml}$ for chondroitin sulfate. Linearity was used to observe whether the results were directly or mathematically proportional to the analyte concentration of a sample in a given range. Linearity met the acceptance criteria if the correlation $(r)$ was $\geq 0.99$ [11]. The results are shown in Table 5.

Limits of detection (LOD) and limits quantitation (LOQ)

The LOD and LOQ are important for determining the lower concentration limit of a substance that can still be determined accurately and precisely. The LOD and LOQ for glucosamine $\mathrm{HCl}$ and chondroitin sulfate were calculated statistically through the line of linear regression from the calibration curve. LOD and LOQ values for glucosamine $\mathrm{HCl}$ and chondroitin sulfate are shown in Table 6.

\section{Selectivity}

The results of $20 \mu$ injections of a placebo solution (matrix tablets and creams) were analyzed under the selected optimum conditions. There was no interference in compound's retention times, which proves that the analytical methods were selective for the glucosamine $\mathrm{HCl}$ and 
Table 3: Optimization of mobile phase composition

\begin{tabular}{|c|c|c|c|c|c|c|c|c|c|}
\hline \multirow[t]{2}{*}{$\begin{array}{l}\text { Mobile phase THF } 0.25 \% \text { in } \\
\text { water-acetonitrile }\end{array}$} & \multicolumn{2}{|c|}{$\begin{array}{l}\text { Retention } \\
\text { time (minutes) }\end{array}$} & \multicolumn{2}{|l|}{ Tf } & \multicolumn{2}{|l|}{ HETP } & \multicolumn{2}{|c|}{$\begin{array}{l}\text { Number of theoretical } \\
\text { plates }(\mathrm{N})\end{array}$} & \multirow[t]{2}{*}{$\mathbf{R}$} \\
\hline & $\mathbf{G}$ & $\mathbf{K}$ & G & $\mathbf{K}$ & $\mathbf{G}$ & $\mathbf{K}$ & $\mathbf{G}$ & $\mathbf{K}$ & \\
\hline$(70: 30)$ & - & - & - & - & - & - & - & - & - \\
\hline \multirow[t]{2}{*}{$(80: 20)$} & 18.440 & 28.456 & 1.020 & 1.024 & $2.33 \times 10^{-3}$ & $1.96 \times 10^{-3}$ & 10740 & 12743 & 11.646 \\
\hline & 18.026 & 27.674 & 1.156 & 1.173 & $2.78 \times 10^{-3}$ & $2.68 \times 10^{-3}$ & 9001 & 9317 & 10.120 \\
\hline \multirow[t]{2}{*}{$(85: 15)$} & 15.922 & 17.614 & 1.480 & 1.271 & $3.03 \times 10^{-3}$ & $3.76 \times 10^{-3}$ & 8238 & 6650 & 2.161 \\
\hline & 19.088 & 21.181 & 1.421 & 1.273 & $3.12 \times 10^{-3}$ & $4.52 \times 10^{-3}$ & 8007 & 5537 & 2.101 \\
\hline \multirow[t]{2}{*}{$(87: 13)$} & 17.235 & 22.247 & 1.687 & 1.277 & $2.96 \times 10^{-3}$ & $4.43 \times 10^{-3}$ & 8441 & 5641 & 5.180 \\
\hline & 16.603 & 21.642 & 1.535 & 1.133 & $3.17 \times 10^{-3}$ & $5.54 \times 10^{-3}$ & 7884 & 4511 & 4.948 \\
\hline \multirow[t]{2}{*}{$(89: 11)$} & 23.379 & 35.332 & 1.639 & 1.296 & $2.93 \times 10^{-3}$ & $5.50 \times 10^{-3}$ & 8531 & 4543 & 7.689 \\
\hline & 23.628 & 35.573 & 1.643 & 1.191 & $2.85 \times 10^{-3}$ & $5.54 \times 10^{-3}$ & 8782 & 4513 & 7.641 \\
\hline \multirow[t]{2}{*}{$(95: 5)$} & 72.764 & & 1.093 & - & $2.57 \times 10^{-3}$ & - & 9730 & - & - \\
\hline & 71.313 & & 1.122 & - & $2.15 \times 10^{-3}$ & - & 11648 & - & - \\
\hline
\end{tabular}

G: Glucosamine HCl, K: Chondroitin sulfate, R: Resolution, THF: Tetrahydrofuran, HETP: Height equivalent totheoretical plate, Tf: Tailing factor, HCl: Hydrochloride

Table 4: Optimization of flow rate

\begin{tabular}{|c|c|c|c|c|c|c|c|c|c|}
\hline \multirow[t]{2}{*}{ Flow rate $(\mathrm{ml} /$ minutes $)$} & \multicolumn{2}{|c|}{$\begin{array}{l}\text { Retention } \\
\text { time (minutes) }\end{array}$} & \multicolumn{2}{|c|}{$\begin{array}{l}\text { Tailing } \\
\text { factor (Tf) }\end{array}$} & \multicolumn{2}{|l|}{ HETP } & \multicolumn{2}{|c|}{$\begin{array}{l}\text { Number of theoretical } \\
\text { plates }(N)\end{array}$} & \multirow[t]{2}{*}{$\mathbf{R}$} \\
\hline & G & $\mathbf{K}$ & G & $\mathbf{K}$ & G & $\mathbf{K}$ & G & $\mathbf{K}$ & \\
\hline $1 / 2$ & 23.695 & 32.111 & 1.116 & 1.073 & $2.14 \times 10^{-3}$ & $2.44 \times 10^{-3}$ & 11696 & 10255 & 7.846 \\
\hline $1 / 5$ & 18.837 & 25.755 & 1.072 & 1.013 & $2.62 \times 10^{-3}$ & $2.66 \times 10^{-3}$ & 9540 & 9402 & 7.545 \\
\hline
\end{tabular}

G: Glucosamine $\mathrm{HCl}, \mathrm{K}$ : Chondroitin sulfate, R: Resolution, $\mathrm{HCl}$ : Hydrochloride

Table 5: Linearity of glucosamine $\mathrm{HCl}$ and chondroitin sulfate

\begin{tabular}{llll}
\hline Solution & a (intercept) & b (slope) & R \\
\hline Glucosamine HCl & -9714206 & 3418646 & 0.9989 \\
Chondroitin sulfate & -1457766 & 21894 & 0.9988 \\
\hline
\end{tabular}

HCL: Hydrochloride

Table 6: LOD and LOQ values

\begin{tabular}{lll}
\hline Solution & LOD $(\boldsymbol{\mu g} / \mathbf{m l})$ & LOQ $(\boldsymbol{\mu g} / \mathbf{m l})$ \\
\hline Glucosamine HCl & 5.51 & 18.38 \\
Chondroitin sulfate & 154.81 & 516.02 \\
\hline
\end{tabular}

LOD: Limits of detection, LOQ: Limits quantitation

Table 7: Accuracy and precision of glucosamine $\mathrm{HCl}$ detection in tablet form

\begin{tabular}{lllll}
\hline $\mathbf{C}(\mathbf{p p m})$ & $\mathbf{X}(\mathbf{p p m})$ & SD & CV (\%) & Recovery (\%) \\
\hline 25.6 & 25.33 & & & 98.93 \\
& 25.84 & 0.26 & 1.01 & 100.94 \\
32 & 25.65 & & & 100.18 \\
& 31.98 & & & 99.93 \\
& 32.08 & 0.06 & 0.20 & 100.26 \\
38.4 & 32.09 & & & 100.28 \\
& 37.81 & & & 98.48 \\
& 37.94 & 0.10 & 0.27 & 98.81 \\
& 37.74 & & & 98.27 \\
\hline
\end{tabular}

C: Concentration, X: Measurable concentration, SD: Standard deviation; CV: Coefficient of variation, HCL: Hydrochloride

chondroitin sulfate derivatives. The chromatograms of selectivity can be seen in Figs. 3 and 4, and the chromatogram of the standard solution is shown in Fig. 5.

\section{Accuracy and precision}

Accuracy is a measure of the closeness of the test result or the average value of the set of data against the true value. In this study, we used the

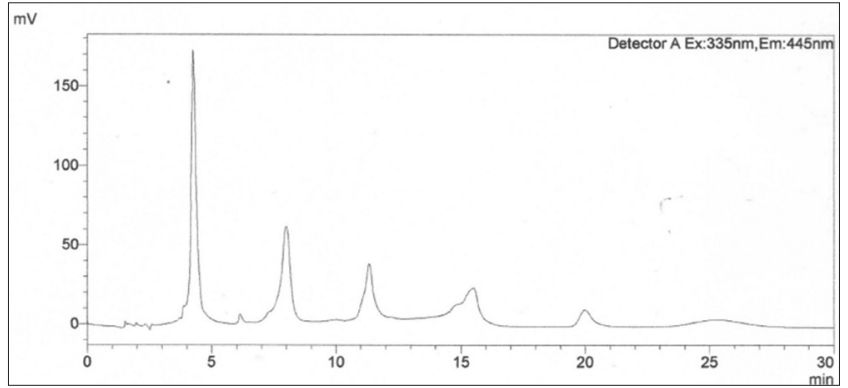

Fig. 3: Chromatogram of selectivity for tablet placebo

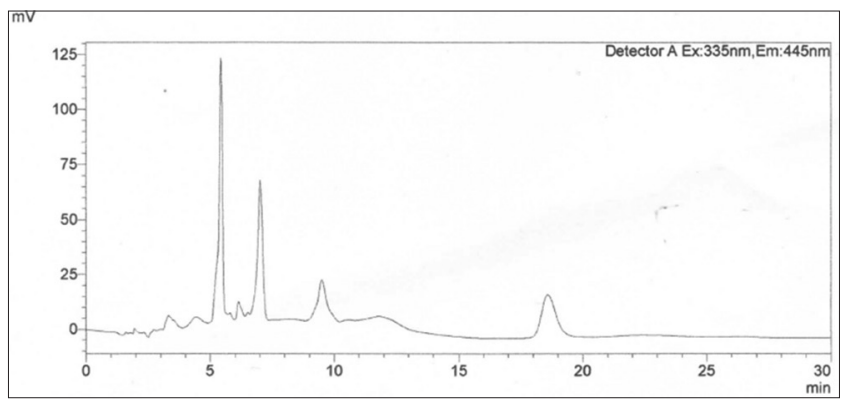

Fig. 4: Chromatogram of selectivity for cream placebo

spiked placebo recovery method with a range of concentrations at $80 \%$, $100 \%$, and $120 \%$ (three replicas per concentration). The accuracy met the acceptance criteria if the recovery value was $98-100 \%$. Precision or repetition tests were measured by calculating the coefficient of variation $(\% \mathrm{CV})$ data of three replicas for each concentration. The acceptance criteria of $\mathrm{CV}$ were $2 \%(\leq 2 \%)$ [12]. The results are shown in Tables 7-10.

Assay

The validated method was used to analyze two samples on the market containing glucosamine $\mathrm{HCl}$ and chondroitin sulfate. Levels were 
calculated using the onepoint measurement method. The average levels of glucosamine $\mathrm{HCl}$ and chondroitin sulfate in tablet form were

Table 8: Accuracy and precision of chondroitin sulfate detection in tablet form

\begin{tabular}{lllll}
\hline $\mathbf{C}(\mathbf{p p m})$ & $\mathbf{X}(\mathbf{p p m})$ & SD & CV (\%) & Recovery (\%) \\
\hline 640 & 646.90 & & & 101.08 \\
& 652.25 & 7.34 & 1.14 & 101.91 \\
& 637.75 & & & 99.65 \\
800 & 806.41 & & & 100.80 \\
& 800.15 & 6.01 & 0.75 & 100.02 \\
& 812.17 & & & 101.52 \\
960 & 841.08 & & & 98.03 \\
& 970.69 & 17.95 & 1.87 & 101.10 \\
& 973.52 & & & 101.41 \\
\hline
\end{tabular}

C: Concentration, X: Measurable concentration, SD: Standard deviation,

CV: Coefficient of variation

Table 9: Accuracy and precision of glucosamine $\mathrm{HCl}$ detection in cream form

\begin{tabular}{lllll}
\hline $\mathbf{C}(\mathbf{p p m})$ & $\mathbf{X}(\mathbf{p p m})$ & SD & $\mathbf{C V}(\%)$ & Recovery (\%) \\
\hline 32 & 32.59 & & & 101.84 \\
& 32.33 & 0.13 & 0.40 & 101.02 \\
& 32.45 & & & 101.42 \\
40 & 40.60 & & & 101.50 \\
& 40.43 & 0.15 & 0.36 & 101.07 \\
48 & 40.31 & & & 100.77 \\
& 48.51 & & & 101.07 \\
& 48.59 & 0.13 & 0.27 & 101.22 \\
& 48.34 & & & 100.70 \\
\hline
\end{tabular}

C: Concentration; X: Measurable concentration; SD: Standard deviation; CV: Coefficient of variation, HCL: Hydrochloride

Table 10: Accuracy and precision of chondroitin sulfate detection in cream form

\begin{tabular}{lllll}
\hline $\mathbf{C}(\mathbf{p p m})$ & $\mathbf{X}(\mathbf{p p m})$ & SD & CV (\%) & Recovery (\%) \\
\hline 320 & 322.63 & & & 100.82 \\
& 322.89 & 0.92 & 0.28 & 100.90 \\
400 & 321.19 & & & 100.37 \\
& 392.10 & & & 98.03 \\
480 & 393.58 & 2.47 & 0.63 & 98.40 \\
& 396.93 & & & 99.23 \\
& 478.65 & & & 99.72 \\
& 480.00 & 0.95 & 0.20 & 100.00 \\
& 480.49 & & & 100.10 \\
\hline
\end{tabular}

C: Concentration; X: Measurable concentration; SD: Standard deviation; CV: Coefficient of variation
$92.76 \%$ and $96.11 \%$, respectively. In cream form, the average levels of glucosamine $\mathrm{HCl}$ and chondroitin sulfate were $101.15 \%$ and $100.33 \%$, respectively. The results are shown in Tables 11-14. Chromatogram samples are shown in Figs. 6 and 7.

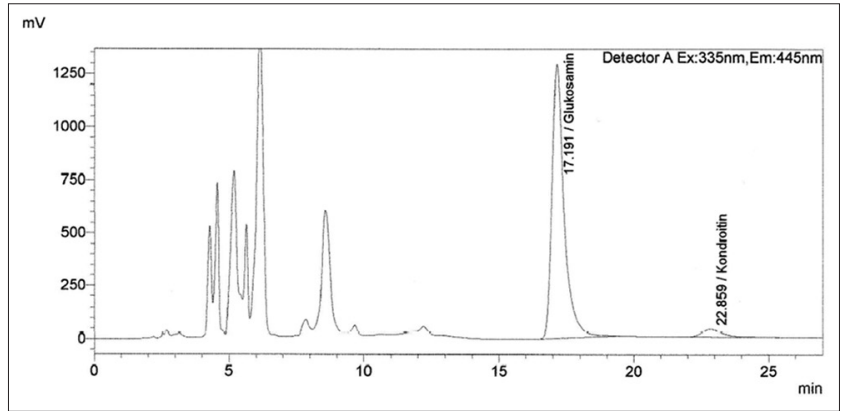

Fig. 5: Chromatogram of standard solutions of glucosamine hydrochloride and chondroitin sulfate

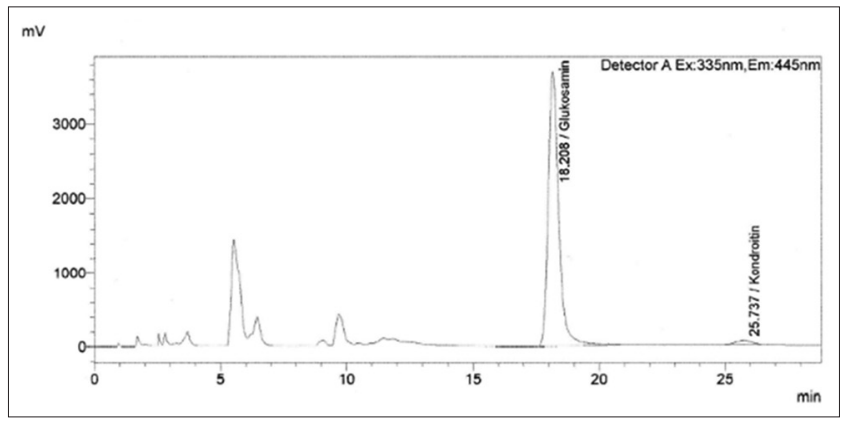

Fig. 6: Chromatogram of tablet sample

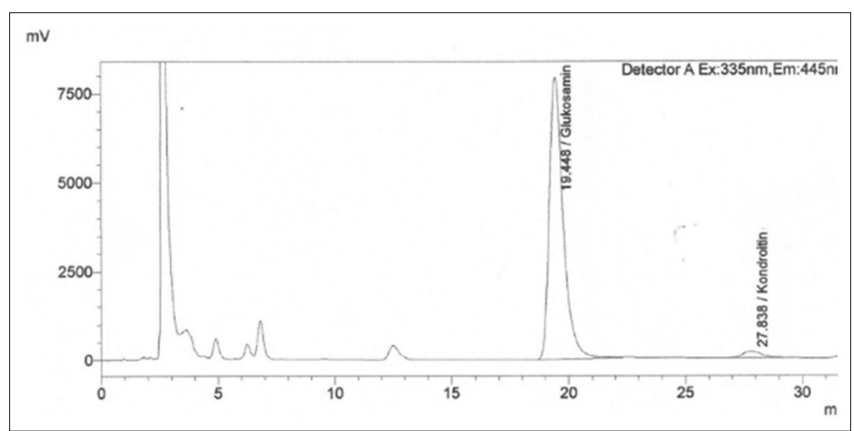

Fig. 7: Chromatogram of cream sample

Table 11: Determination of glucosamine $\mathrm{HCl}$ levels in tablet form

\begin{tabular}{|c|c|c|c|c|}
\hline$C(p p m)$ & Standard area of glucosamine $\mathrm{HCl}$ & Sample area of glucosamine $\mathrm{HCl}$ & $\begin{array}{l}\text { Measurable } \\
\text { concentration (ppm) }\end{array}$ & $\begin{array}{l}\text { Measurable } \\
\text { concentration (\%) }\end{array}$ \\
\hline 20 & 110857856 & $\begin{array}{l}107179978 \\
100539254 \\
100793341\end{array}$ & $\begin{array}{l}19.34 \\
18.14 \\
18.18\end{array}$ & $\begin{array}{l}96.68 \\
90.69 \\
90.92\end{array}$ \\
\hline
\end{tabular}

C: Concentration, HCL: Hydrochloride

Table 12: Determination of chondroitin sulfate levels in tablet form

\begin{tabular}{lllr}
\hline C (ppm) & Standard area of chondroitin sulfate & Sample area of chondroitin sulfate & $\begin{array}{l}\text { Measurable } \\
\text { concentration (ppm) }\end{array}$ \\
\hline 600 & 2585195 & 2489213 & $\begin{array}{l}\text { Measurable } \\
\text { concentration (\%) }\end{array}$ \\
& & 2508669 & 577.72 \\
& & 2455966 & 582.24 \\
\hline
\end{tabular}

C: Concentration 
Table 13: Determination of glucosamine $\mathrm{HCl}$ levels in cream form

\begin{tabular}{lllll}
\hline $\mathbf{C}(\mathbf{p p m})$ & Standard area of glucosamine HCl & Sample area of glucosamine HCl & $\begin{array}{l}\text { Measurable } \\
\text { concentration (ppm) }\end{array}$ & $\begin{array}{l}\text { Measurable } \\
\text { concentration (\%) }\end{array}$ \\
\hline 80 & & & 82.14 & 102.67 \\
& 320059616 & 328605087 & 82.11 & 102.64 \\
& & 328510670 & 82.10 & 102.63 \\
\hline
\end{tabular}

C: Concentration, HCL: Hydrochloride

Table 14: Determination of chondroitin sulfate levels in cream form

\begin{tabular}{llll}
\hline $\mathbf{C}(\mathbf{p p m})$ & Standard area of chondroitin sulfate & Sample area of chondroitin sulfate & $\begin{array}{l}\text { Measurable } \\
\text { concentration (ppm) }\end{array}$ \\
\hline 900 & 10382934 & 10431472 & 904.21 \\
& & 10400356 & 901.51 \\
& & 10419917 & 903.21 \\
\hline
\end{tabular}

C: Concentration

\section{CONCLUSION}

The optimum conditions for determining glucosamine $\mathrm{HCl}$ and chondroitin sulfate in tablet and cream forms included the use of HPLC with a fluorescence detector at $\lambda e x=335 \mathrm{~nm}$ and $\lambda \mathrm{em}=445 \mathrm{~nm}$, and a YMC-Triart ${ }^{\circledR}$ C18 column (length $250 \mathrm{~mm}$, diameter $4.6 \mathrm{~mm}$, and particle size $5 \mu \mathrm{m}$ ), a mobile phase of THF in water-acetonitrile (87:13), and a flow rate of $1.5 \mathrm{ml} /$ minute. The optimum conditions for the hydrolysis of chondroitin sulfate involved $\mathrm{NaOH}$ and heating for 30 minutes at $60^{\circ} \mathrm{C}$. A mixture of glucosamine $\mathrm{HCl}$, and chondroitin sulfate was derivatized with $50 \mu \mathrm{l}$ of OPA/2-ME reagent, and then incubated for 2 minutes, and $20.0 \mu \mathrm{l}$ was injected into the HPLC system. The validation method for glucosamine $\mathrm{HCl}$ and chondroitin sulfate met the acceptance criteria of accuracy, precision, selectivity, and linearity.

\section{REFERENCES}

1. Tjahjono DH, Slamet IS, Sasanti TD. Analysis of glucosamine in cream dosage form and difussion liquid by high performance liquid chromatography. J Ion Exch 2007;18(4):1420-1.

2. Nagarajan P, Sathis KD, Somsubhra G, Harani A, Maheswaran N, David B. Method development and validation for glucosamine and chondroitin sulphate in soflet form by RP-HPLC. Res Rev J Pharm Anal 2013;2:6-10

3. Pratiwi AI. Diagnosis and Treatment Osteoarthritis, Thesis. Indonesia: Universitas Lampung; 2015.
4. Andriani S. Optimasi derivatisasi glukosamin hidroklorida dengan 9-fluorenilmetoksikarbonil klorida (FMOC-Cl) secara kromatografi cair kinerja tinggi-fluoresensi. Depok: Universitas Indonesia; 2012.

5. Topping J. A review of methods available for the determination of chondroitin sulphates in supplements. United Kingdom: Laboratory of the Government Chemist Queens Road Teddington Middlesex; 2012.

6. David JI, Roman M, Zhou J, Hildreth J. Determination of chondroitin sulphate content in raw materials and dietary supplements by high performance liquid chromatography with ultraviolet detection after enzimatic hydrolysis. J AOAC Int 2007;90(3):659-69.

7. Vaclavikova E, Frantisek K. Isotachophoretic determination of glucosamine and chondroitin sulphate in dietary supplements. Czech J Food Sci 2013;31:55-65.

8. Dionex Corporation. Determination of Glucosamine in Dietary Supplements Using HPAE-PAD; Application Note 197, LPN 2001. Sunnyvale, CA: Dionex Corporation; 2008.

9. Lee KS, Drescher DG. Derivatization of cysteine and cystine for fluorescence amino acid analysis with the o-phthaldialdehyde/2mercaptoethanol reagent. J Biol Chem 1979;254(14):6248-51.

10. Rhee WM, Richard AB. Glycisaminoglycan-Synthetic Polymer Conjugates. European Patent Apllication, Report; 1995.

11. Assocation of Official Analytical Chemist (AOAC). Guidelines for Single Laboratory Validation of Chemical Methods for Dietary. Available from: https://www.aoac.org/aoac prod imis/AOAC Docs/ StandardsDevelopment/SLV_Guidelines_Dietary_Supplements.pdf.

12. Harmita H. Buku Ajar Analisis Fisikokimia. Depok: Universitas Indonesia; 2006 